\title{
The Relationship between Parenting Stress and Perceived Children's Social Problem Behavior among Chinese Working Mothers
}

\author{
Chew Xing Jiun, Wan Marzuki Wan Jaafar, and Nor Mazlina Ghazali
}

\begin{abstract}
This study examines the relationship between parenting stress and perceived children's social problem behavior. The sample consists of 100 Chinese working mothers were sampled by cluster sampling methods. Parenting Stress Index-short Form and Eyberg child Behavior Inventory were employed to measure the parenting stress and children social problem behavior respectively. The result revealed that parenting stress is significantly positive correlated with perceived children social problem behavior in intensity $(r$ $=.431 * *, p<0.01)$ and problem score $(r=.716 * *, p(0.0 I)$. Besides, parental distress $\left(r=.340^{* *}, p<0.01\right)$, parent child dysfunction interaction $\left(r=.398^{* *}, p<0.01\right)$ and difficult child $(r=.389 * *, p<0.01)$ also moderately associated with perceived children social problem behavior in intensity score. The findings also noted parental distress $(r=.435 * *, p<0.01)$, parent child dysfunction interaction $\left(r=.731^{* *}, p<0.01\right)$ and difficult child $(r=.672 * *, p<0.01)$ also moderately associated with perceived children social problem behavior in problem score. Interestingly, the result showed household income $(r=$ $-.233 * *, p<0.01)$ and numbers of children $(r=.333 * *, p<0.01)$ are related to parenting stress. The result showed the higher the working hours, the lower the parenting stress $(r=-.424 * *, p<$ 0.01). Hence, this study gives a guideline for the policy makers and counselors to design program which can benefit the parents and children as well.
\end{abstract}

Index Terms-Parenting stress, children's social problem behavior.

\section{INTRODUCTION}

Psychologists agree that nurturing style procedures an adult model that a child can imitate. There is a saying that "children fail to learn, but never fail to imitate", nurturance therefore is likely to build a positive feelings towards others. A child who enjoys warmth as well as affection in the family circle will certainly orientate more positively towards developing constructive social relations with others and likely follow the instruction of others. According to attachment theories proposed [1] a close and secure parent-child relationship influences the social behavior of the child in future time.

Since parents play an important role in shaping children's social behavior, mothers appear more often in observation compared with fathers because mothers mostly are the first person children start to interact with. Infants who are neglected and separated from their mothers will become depressed and even feel panic from time to time.

Manuscript received August 21, 2014; revised October 13, 2014.

Wan Marzuki Wan Jaafar is with the Universiti Putra Malaysia, 43400 UPM Serdang, Selangor, Malaysia (e-mail: wanmarzuki@upm.edu.my).
Nowadays, the whole world is experiencing of this drastic transformation in the nature and character of family, work, and society because mother who owns children enter and remain in the labor force in unprecedented number. As the number of working mothers increase significantly, women these days have more roles to play than ever before, and they are expected to fulfill more social responsibility and other demands of society.

They are not only demanded to work outside the home, but also have the responsibilities for taking care of their children. As playing the role of wives and mothers, women contribute to the family economy when necessary, but the fact is this seriously conflicts with their principals of home making responsibilities. Thus, women were suffering stress because of workload in workplace and the family responsibilities.

Another concern is, parenting stress is not only related to the major life event, but also is being covered with the perceptive of child rearing. Parenting stress is created when there is a gap between the expectation of the parents themselves and children. Employment of mother has become a noticeable issue in our society since nowadays many people predict that working mother is not able to balance family and work, leading serious social problem to the next generation. The trend of working mother, however, has already been globalized such that finding a solution should be more valuable than preventing it.

In general, the purpose of this study is to determine the relationship between parenting stress and perceived children social problem behavior among working mothers. While, the specific objectives are:

- To describe the personal background (age, education level, income, working hours, numbers of children, work nature and types of work) of working mothers involved in the study.

- To determine the relationship between selected personal background characteristic (income, working hours, numbers of children) and parenting stress among working mothers.

- To determine the relationship between working mothers' parenting stress (parenting distress, parent- child dysfunction interaction, difficult child) and their perceived children social problem behavior (intensity and problem) among working mothers.

\section{RESEARCH MethodOlOGY}

This is a correlation survey to examine the relationship between parenting stress of working mother and perceived 
children social problem behavior.

\section{A. Research Design}

A correlational research design was employed to evaluate the strength of relations between variables [2].

\section{B. Population}

The population was set to focus on eight preschools randomly that picked from the preschool list in Malaysia. The population was sampled by cluster sampling methods. Before the eighth preschool was selected, one school had been selected by using the fish bowl technique as a sample of pilot study.

\section{Sample}

100 respondents were chosen from the table of random numbers. According to [2], a good representative of the population is relatively important than its size of the sample. Therefore, size sample of 100 is large enough to represent the Chinese working mothers who have preschool children in Malaysia.

\section{Instrumentation}

A questionnaire was employed to measure the variable of the study. The first part just recorded background information of the respondent including maternal age, salary per month, working hours, and numbers of children, educational level, mother's position, and work nature; the second part tested the parenting stress of working mothers, namely Parenting Stress Index-Short Form (PSISF) [3] whereas third part is Eyberg Child Behavior Inventory (ECBI) [4] (see Table I).

\begin{tabular}{|c|c|c|c|}
\hline Measurement & $\begin{array}{l}\text { Original } \\
\text { Study }\end{array}$ & $\begin{array}{l}\text { Pilot Study } \\
\quad(n=30)\end{array}$ & $\begin{array}{c}\text { Current Study } \\
(n=100)\end{array}$ \\
\hline \multicolumn{4}{|l|}{$\begin{array}{c}\text { Children Social } \\
\text { Behavior }\end{array}$} \\
\hline Intensity & .86 & .86 & .86 \\
\hline Problem & .79 & .90 & .89 \\
\hline Parenting Stress & .91 & .92 & .91 \\
\hline $\begin{array}{c}\text { Parental Distress } \\
\text { Parent-Child }\end{array}$ & .87 & .78 & .77 \\
\hline $\begin{array}{l}\text { Dysfunctional } \\
\text { interaction }\end{array}$ & .80 & .82 & .84 \\
\hline Difficult Child & .91 & .82 & .86 \\
\hline
\end{tabular}

\section{E. Data Analysis}

In this study, descriptive statistics are used to explain the general distribution of the respondents' personal background information, parenting stress level and their children social problem behavior. The application of Pearson correlation was to measure the strength of the linear relationship between two variables when the both data were continuous. For accuracy, confidence interval of the study was set at $p<.05$.

\section{RELIABILITY OF THE INSTRUMENT}

Going through this process, researcher would know the feasibility of using the Parenting stress short form (PSI-SF) and ECBI test and to amend the instruments in order to suit the respondent's context.

\section{FINDING}

The aim of this study was to determine the relationships between the parenting stress and perceived children social behavior problem among working mothers. There were around 100 respondents participated in this study through cluster sampling methods. To accomplish this objective, the data collections have been done and have been analyzed by using the SPSS version 21(see Table II).

\section{A. Description of Personal Background of the Respondents (Age, Education Level, Income, Working Hours, Numbers of Children, Work Nature and Types of Work) of Working Mothers Involved in the Study}

\begin{tabular}{|c|c|c|c|}
\hline Variable & n $(\%)$ & Mean & SD \\
\hline Age (years old) & & 35.56 & 7.99 \\
\hline$<30$ & $22(22 \%)$ & & \\
\hline $30-40$ & $59(59 \%)$ & & \\
\hline$>40$ & $19(19 \%)$ & & \\
\hline $\begin{array}{l}\text { Working Hours } \\
\text { (hours per day) }\end{array}$ & & 8.12 & 1.03 \\
\hline$<8$ & $12(12 \%)$ & & \\
\hline $8-9$ & $77(77 \%)$ & & \\
\hline$>9$ & $11(11 \%)$ & & \\
\hline \multicolumn{4}{|l|}{ Education Level } \\
\hline Primary & $0(0 \%)$ & & \\
\hline Secondary & $13(13 \%)$ & & \\
\hline Tertiary & $87(87 \%)$ & & \\
\hline \multicolumn{2}{|l|}{ Monthly Salary(RM) } & 5995.00 & 2525.00 \\
\hline$<4000$ & $18(18 \%)$ & & \\
\hline 4000-7000 & $64(64 \%)$ & & \\
\hline$>7001-10000$ & $5(5 \%)$ & & \\
\hline$>10000$ & $13(13 \%)$ & & \\
\hline \multicolumn{4}{|l|}{ Work Nature } \\
\hline Permanent & $90(90 \%)$ & & \\
\hline Temporary & $10(10 \%)$ & & \\
\hline \multicolumn{4}{|l|}{ Types of work } \\
\hline White Collar & $94(94 \%)$ & & \\
\hline Blue Collar & $6(6 \%)$ & & \\
\hline $\begin{array}{l}\text { Numbers of } \\
\text { Children }\end{array}$ & & 2.13 & 0.837 \\
\hline$<2$ & $23(23 \%)$ & & \\
\hline $2-3$ & $71(71 \%)$ & & \\
\hline$>3$ & $6(6 \%)$ & & \\
\hline
\end{tabular}

The respondents' age was ranged from 27 to 52 years old $($ mean $=35.41$ years old, standard deviation $=7.981)$. The study levels respondents' educational standard into three levels which are level of primary, secondary and tertiary; and are precisely recorded. The findings reported that most of the respondents fall in to the category of tertiary which is $87 \%$. The current study also has shown the trend of mothers who are working nowadays majorly are doing permanent job, which are $90 \%$ overall. For working hours, the report shows $12 \%$ respondents classified below 8 hours. Most of the respondents, $77 \%$ were under the range 8 to 9 hours per day which is considered as normal office hours for the Malaysian. There was only $11 \%$ of the respondents work more than 9 hours per day.

\section{B. Inferential Data Analysis and Result}

In order to examine the relationship between personal background, parenting stress and perceived children social behavior problem among working mothers, the Pearson Correlation Test was administered to determine the 
relationship between independent variables such as parenting stress (parental distress, parent-child dysfunction interaction, difficult child), income, working hours and numbers of children, and dependent variables which is children social behavior (intensity, currently problematic behavior) among the working mothers. Due to the PSI consists of three subscales, namely, PSI-PD, PSI- and ECBI, where the later consists of two subscales which are ECBI- intensity and ECBI-problem, thus, it is important to analyze the subscale as well.

\section{To Determine the Relationship between Selected Personal Background Characteristic (Income, Working Hours, Numbers of Children) and Parenting Stress among Working Mothers}

From Table III, the result noted that there was a significant relationship between the household income and parenting stress $(r=-.233 * *, p<.01)$. The weak form of negative direction of this relationship shows that the more the household income, the lower the parenting stress from the working mothers. The result is consistent with the previous findings that family income was associated with parenting stress [5]. [5] revealed, even though financial problem produces stress to children and parents, income alone does not determine the parenting stress. Another research from [6]. noted financial burden can cause the stress which will be able to affect the outcome of the parents to satisfy their children' needs and influence the parent emotion. The result gives a possibility that household income might able to contribute and increase the level of parenting stress. Thus, further examination is suggested for the future researchers. Refer Table IV for further detail.

TABLE III: THE RELATIONSHIP BETWEEN HOUSEHOLD INCOME AND PARENTING STRESS AMONG WORKING MOTHERS

\begin{tabular}{lcc}
\hline \hline $\begin{array}{l}\text { Personal } \\
\text { background }\end{array}$ & \multicolumn{2}{c}{ Parenting Stress } \\
\hline Household Income & Correlation $(r)$ & Significant (2 tailed) \\
& $r=-.233 * *$ & $p=.000$ \\
\hline
\end{tabular}

Remark: ** Significance of Pearson's correlation at $p<.01$ level

TABLE IV: THE RELATIONSHIP BETWEEN MOTHER'S WORKING HOURS AND PARENTING STRESS AMONG WORKING MOTHERS

\begin{tabular}{lll}
\hline \hline Personal background & \multicolumn{2}{c}{ Parenting Stress } \\
\hline Working hours per day & Correlation $(\boldsymbol{r})$ & Significant (2 tailed) \\
& $R=-.424^{* *}$ & $p=.000$ \\
\hline \hline
\end{tabular}

Remark: ** Significance of Pearson's correlation at $p<.01$ level

The present result yields that there was a negative significant relationship between mother's working hours and score of parenting stress $(r=-.424 * *, p<.01)$. A medium negative relationship exists between the mothers working hours per day and parenting stress among the working mothers. It has shown that the shorter the working hours of the mother, the higher the parenting stress score of the mother. Interestingly, this is contradicted with the study of [7] found the long hours would contribute negative impact for the parenting stress. The main reason might due to the culture of Chinese people that they prefer putting more effort in working rather than taking care of their child. However, current study suggests the further examination should be done. Refer Table V for further detail.

Table VI showed there was a significant relationship between numbers of children and parenting stress $\left(r=.333^{* *}\right.$, $p<.01)$. The positive weak strength relationship is found from the result. The result indicated the greater the numbers of children, the higher the parenting stress score. The result also supported by [8] who found the association between the numbers of children and parenting stress. According to [9], numbers of children also related to higher level of parenting stress. Therefore, numbers of children cannot be ignored in determining the parenting stress as the contribution of parenting stress probably due to the factor of total numbers of children.

Hence, the contribution of parenting stress is probably and partially due to the total numbers of children. It was believed that more children required more effort in taking care of and also satisfying their children demands. As a result, the situation of having more children might be able to create bigger discrepancies between the expectation of working mothers for themselves and their child. The greater the gap between the expectation and the reality they come upon, the higher the tendency to create the parenting stress. Therefore, numbers of children cannot be ignored in determining the parenting stress as the contribution of parenting stress probably resulted by the factor of total numbers of children.

TABLE V: THE RELATIONSHIP BETWEEN NUMBERS OF CHILDREN AND PARENTING STRESS AMONG WORKING MOTHERS

\begin{tabular}{lll}
\hline $\begin{array}{l}\text { Personal } \\
\text { background }\end{array}$ & \multicolumn{1}{c}{ Intensity } \\
\hline Numbers of children & Correlation (r) & $\begin{array}{l}\text { Significant } \\
(2 \text { tailed })\end{array}$ \\
& $r=.333^{* *}$ & $p=.000$ \\
\hline \hline
\end{tabular}

Remark: ** Significance of Pearson's correlation at $p<.01$ level

\section{To Determine the Relationship between Working Mothers' Parenting Stress (Parenting Distress, Parent- Child Dysfunction Interaction, Difficult Child) and Their Perceived Children Social Problem Behavior (Intensity and Problem) among Working Mothers.}

1) The Relationship between total parenting stress and perceived children social problem behavior

From Table VII, the research finding manifested that there is a significant relationship between parenting stress and perceived children social problem behavior (ECBI intensity) among working mothers $\left(r=.431^{* *}, p<.01\right)$. The positive direction of the moderate strength relationship showed the higher the parenting stress, the more frequently the social problem behavior of their children among the working mothers.

Thus, the result indicated the difficulty that comes from the demands of being a parent has related with the intensity of children social behavior problem. Moreover, the research findings also shown there is a significant strong relationship between parenting stress and perceived children behavior problem (ECB-problem) among working mothers $(r=.716$ $* *, p<.01)$.

It can be clearly seen that the positive direction has shown the higher the parenting stress, the more number of existence of current problem can be detected. The findings were similar 
with [10] report that there was a relationship between parenting stress and children social behavior problem. However the pervious targeted group focused on the children with autistic spectrum disorders (ASDS). At the same time, the research of [11] also as expected, showing the parenting stress was associated to the child behavior problem. Another direct relationship between parenting stress and children social behavioral problem in classroom was significantly shown by [12].

TABLE VI: THE RELATIONSHIP BETWEEN PARENTING STRESS AND PERCEIVED CHILDREN SOCIAL BEHAVIOR PROBLEM (ECBL-INTENSITY) AMONG WORKING MOTHERS

\begin{tabular}{lll}
\hline \hline Parenting Stress & Intensity \\
\hline & Correlation $(r)$ & $\begin{array}{l}\text { Significant } \\
(2 \text { tailed })\end{array}$ \\
& $r=.431 * *$ & $p=.000$ \\
\hline \hline
\end{tabular}

Remark: ** Significance of Pearson's correlation at $p<.01$ level

TABLE VII: THE RELATIONSHIP BETWEEN PARENTING STRESS AND Perceived Children Social Behavior Problem (ECBI-Problem)

\begin{tabular}{cl}
\hline \hline Parenting Stress & Problem \\
\hline Correlation $(r)$ & $\begin{array}{l}\text { Significant } \\
(2 \text { tailed })\end{array}$ \\
$r=.716^{* *}$ & $p=.000$ \\
\hline \hline Remark: ** Significance of Pearson's correlation at $p<.01$ level
\end{tabular}

\section{2) The relationship between parental distress and intensity of children social behavior problem}

Results appear in Table VIII, the research finding manifested that there is a moderate significant relationship between parental distress and intensity of children social problem behavior among working mothers $\left(r=.340^{* *}, p<\right.$ $01)$. At the same time, parental stress proved to be associated with the children social behavior problem among the working mothers $\left(r=.435^{* *}, p<01\right)$ as the relationship considered as moderate strength. From this result, this can be concluded that parental distress has been shown in relation of perceived children behavior in term of intensity and problem scale.

TABLE VIII: THE RELATIONSHIP BETWEEN PARENTING DISTRESS AND PERCEIVED CHILDREN SOCIAL BEHAVIOR PROBLEM (ECBI-INTENSITY) AMONG WORKING MOTHERS

\begin{tabular}{|c|c|c|}
\hline \multirow{2}{*}{ Parenting Stress } & \multicolumn{2}{|c|}{ Intensity } \\
\hline & Correlation $(r)$ & $\begin{array}{c}\text { Significant } \\
\text { (2 tailed) }\end{array}$ \\
\hline & $r=.340^{* *}$ & $p=.001$ \\
\hline
\end{tabular}

This is compatible with the expectation because according to [13], children with depressed mothers not only inherit the risk of the developmental obstacle of psychopathology, but also intend to increase their child behavior problems. In other words, it is possible that the depressed mother may able to give impact to their child social problem behavior. Another explanation could be maternal depression shows a relationship but negative perception towards their children problem behavior [14]. However, the study is based on the correlational analyses; it cannot determine the direction of the effect.

TABLE IX: THE RELATIONSHIP BETWEEN PARENTING DISTRESS AND Perceived Children Social Behavior Problem (ECBL-Problem) AMONG WORKING MOTHERS

\begin{tabular}{lcc}
\hline \hline Parenting Stress & \multicolumn{2}{c}{ Problem } \\
\hline Correlation $(r)$ & Significant (2 tailed) \\
$r=.435^{* *}$ & $p=.000$ \\
\hline \hline Remark: ** Significance of Pearson's correlation at $p<.01$ level
\end{tabular}

As presented in Table IX, the result indicated that there was a moderate strength significant relationship between parent-child dysfunction interaction and intensity of children social behavior problem among working mothers $(r=398 * *$, $p<01)$. The positive relationship has shown the higher the unsatisfactory parent-child interaction, the more severity of the children social behavior problem. Besides, the result has also shown there was a strong significant relationship between parent-child dysfunction interaction and perceived children social behavior problem (ECBI problem) $(r=731 * *$, $p<.01)$ in Table $\mathrm{X}$. This indicates that the more negative feelings the respondents got from the interaction with their child, the more the mother perceived currently problem of their child. The result was consistent with some of the earlier study, which found the association between the subscales of parent-child dysfunction interaction of the PSI-SF and children social behavior problem.

TABLE X: THE RELATIONSHIP BETWEEN PARENTAL CHILD DYSFUNCTION INTERACTION AND PERCEIVED CHILDREN SOCIAL BEHAVIOR PROBLEM (ECBL-INTENSITY) AMONG WORKING MOTHERS

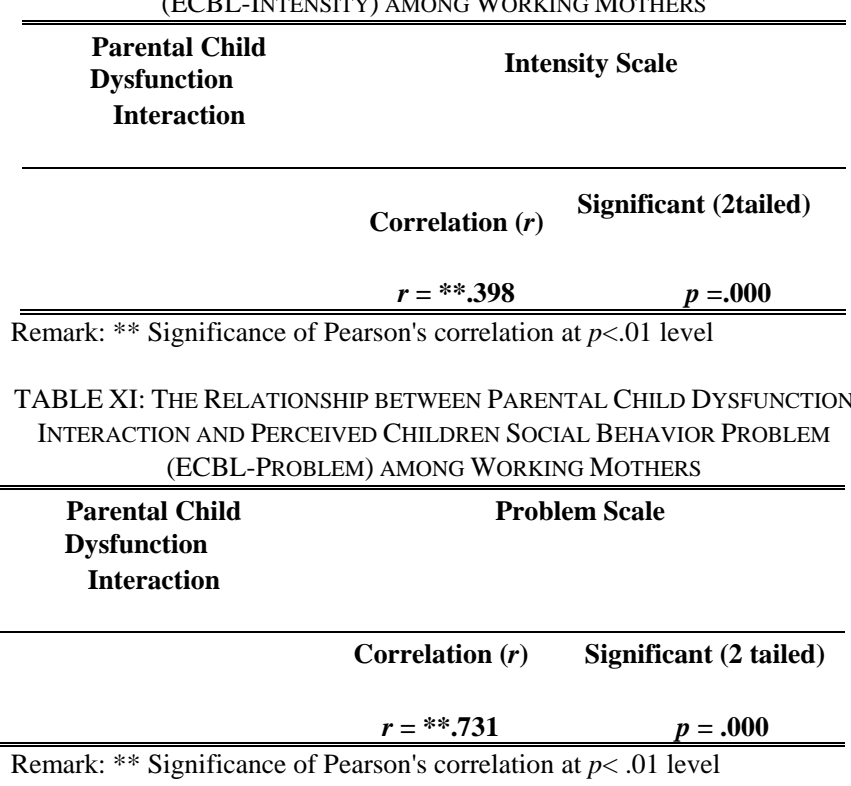

The current result also partially supported the research of [15] which revealed characteristics of the parent child relationship are linked with the child wellbeing and psychological function of the parents. The possibility might be the more mother's negative feeling of the interaction with children; their greater the child has negative emotion control. This indirectly will contribute to their disruptive behavior as well. [16] also posited good quality of parent-child 
relationship is able to enhance the better outcome for the children with depressed mother. Apparently, the positive quality of parent-child relationship has to be promoted for the working mothers in order to increase the good outcome of the children physically and mentally.

As shown at Table XI, the finding noted that there was a moderately positive relationship between the difficult child and intensity of children social behavior problem among the working mothers $\left(r=.389^{* *}, p<0.01\right)$. The positive direction indicated the more the parents assess their child as difficult child, the more severe of the child social behavior problem is. Also, it has shown in the table**, the findings reported that there was a significant relationship between difficult child and currently problem behavior among the working mothers $(r=.672 * *, p<.01)$ as the result falls into the moderate range of the correlation. The difficult child is a child who has poor temperament which is able to cause a person hardly to control his emotion and self-discipline. The findings confirmed the research conducted by [17] which noted that children with difficult temperament are more vulnerable to indiscipline compared to the easy child (see Table XII-Table XIII).

TABLE XII: THE RELATIONSHIP BETWEEN DIFFICULT CHILD AND PERCEIVED CHILDREN SOCIAL BEHAVIOR PROBLEM (ECBL-INTENSITY) AMONG WORKING MOTHERS

\begin{tabular}{c}
\hline Difficult Child \\
Correlation $(r) \quad$ Significant (2 tailed) \\
$r=.389 * * \quad p=.000$ \\
\hline \hline Remark: ** Significance of Pearson's correlation at $p<.01$ level
\end{tabular}

TABLE XIII: THE RELATIONSHIP BETWEEN DIFFICULT CHILD AND Perceived Children Social Behavior Problem (ECBL-Problem) AMONG WORKING MOTHERS

Difficult Child $\quad$ Problem Scale

\begin{tabular}{cc} 
Correlation $(r)$ & Significant (2 tailed) \\
$r=.672 * *$ & $p=.000$ \\
\hline \hline Remark: ** Significance of Pearson's correlation at $p<.01$ level
\end{tabular}

Remark: ** Significance of Pearson's correlation at $p<.01$ level

\section{DISCUSSION AND IMPLICATION}

There was a significant weakly relationship between household income and parenting stress $(r=-.233 * *, p<.01)$. The result was supported by the similar earlier research which showed the family income was associated with parenting stress [5]. There are many previous findings found that the stress made by financial burden will affect the ability of a parents in satisfying their child's demand and also contribute to the parent emotional distress [6]. However, the previous study noted that income alone was not the main predictor of the parenting stress as family circumstances also has to be included for anticipating the factor that contribute to the parenting stress in overall.

From the collected result, the current research noted that mother's working hours was also related to the parenting stress of the mother $(r=424 * *, p<.01)$. Thus, the result showed moderate significant relationship between mother's daily working hours and parenting stress. The present study was not coherent with some of the studies with indicated long working hours will create negative implication for the parenting stress [7]. The outcome of the current study is the shorter the working hours of a mother, the more parenting stress a mother intend to gain. From the result, the prediction of the unexpected result might because of the Chinese culture in Malaysia as most of the Chinese mothers prefer working rather than taking care of their child. Thus, the lesser their time exposure to their child might reduce their stress of parenting. As known, parenting is not an easy task that it needs more patience in taking care and fulfilling the demand of children. Working oriented mothers with more hours might have relatively less time spent on their children so does the less patience. For further understanding the nature of Chinese working mother in Malaysia, future study is suggested to figure this situation more deeply.

In addition, the result also manifested that there was a significant positive relationship between the numbers of children and parenting stress $\left(r=.333^{* *}, p<.01\right)$. The result can be interpreted that the more children the respondents have had, the higher the level of parenting stress is detected. By referring to the study conducted by [8], which provided a similar result, stating that the strong association was found between the numbers of children and parenting stress. The only difference is that current research only showed a weak association between the numbers of children and parenting stress. The likelihood of this happening might because of difficulty for those working mothers to handle more children life events that creates negative judgment towards task of parenting. Even though the increasing numbers of children might able to influence the stress of parents, this study is exclusively based on the correlation analysis, it could not completely determine the effect or predict its upcoming outcome and it might be because of other factor. Thus, the further examination has to be done for the further research.

Through the findings, apparently can be seen there was a relationship between the parenting stress and perceived children social problem behavior, ECBI- intensity $(r$ $\left.=.431^{* *}, p<.01\right)$ and ECB1-problem $\left(r=.716^{* *}, p<.01\right)$. This can be interpreted that the greater amount of the parenting stress, the greater the frequency of children social problem behavior and the greater the currently problem of the children among the working mothers. This study confirms the previous study which noted the parenting stress was related to the child behavior [11].

Since this is a study to examine correlation, it does not show the directionality of the effect. However, a few past researches give comment that parenting stress and child social behavior problem may have bidirectional relationship. This is because it is predicted that children who have had severe behavioral problem implicitly increases the stress parenting level of their parents [18] and also the risk of bringing side effect and vice versa. If bidirectional relationship really works, there is a possibility that the stress of parenting might also directly have an impact on children. The stress of parenting is believed that it can influence the parents' emotion.

As a result, this negative environment and atmosphere 
might also worsen the children socio-emotional behavior. Another explanation of this situation is since the children behavior is rated by respondents itself, which in turn gives a possible thought that the working mothers (respondents) who have experienced high level of stress may intuitively rate their children are having severe problem behavior. In other words, the result of child behavior (negative way) might made by the perception of the mother, compared to an actual occurrence. The result has brought a great suggestion that more training programs and seminar should have to be conducted for parents in order to strengthen their parenting skills and coping strategies.

The Parenting stress Index (PSI) consists of three subscales to examine Parental Distress, Parent-Child Dysfunctional Interaction and Difficult Child. Three of these domains have been used in current study to examine the relationship regards children social behavioral problem. As expected, the current analysis has shown, Parental Distress, Parent-Child Dysfunctional Interaction and Difficult Child were related with the children social problem behavior in term of intensity and problem scale. In other words, Parental Distress, Parent-Child Dysfunctional Interaction and Difficult Child served as a possible factor that can contribute to a child social problem behavior.

The research finding indicated parental distress was associated with intensity scale $(r=.340 * *, p<.01)$ and problem scale $\left(r=.435^{* *}, p<.01\right)$ of children behavioral problem among working mothers. The result has supported by the statement of [13] which stated that depressed mothers are high risk in increasing the behavioral problem of their child and psychopathology problem. Besides, Parent- Child Dysfunctional Interaction also related to intensity scale mothers $\left(r=.398^{* *}, p<.01\right)$. and problem scale $(r=.737 * *$, $p<.01)$ of children behavioral problem among working mothers. The result demonstrated that the more negative feelings the respondents got from the interaction with their child, the higher the score of the children social problem behavior. The study confirms the findings and found similar result with the research conducted by [19]. The result brought the possibility that mothers with more negative feelings of the interaction with children were able to affect the child emotional control, resulting their child to have more troublesome behavior. Another explanation could be, the more negative feelings the respondents got from the interaction with their child, the greater possibility parents would perceive their child to be more problematic.

The third domain, difficult child; also has a significant relationship with children behavioral problem in term of the intensity scale $\left(r=.389^{* *}, p<.01\right)$ and problem scale $(r$ $=.672 * * p<.01)$. Every child has dissimilar temperament. The difficult child is a child who has poor temperament which is able to cause a person hardly to control emotion and behavioral problem. The result confirms the statement of as it showed the higher the mother rate their child as difficult child, the higher the score of children social problem behavior.

Through the result, in overall, this study confirms the previous studies' As expected' the current result posited that there was a significant relationship between the total parenting stress and perceived children social problem behavior in term of intensity and problem scale. In addition, the study also found Parental Distress, Parent-Child Dysfunctional Interaction and Difficult Child were related to perceived child social behavior problem among the working mothers. Therefore, policy makers should concern about the working mother as effective programs of early intervention that should be addressed from preventing the development of parenting stress which is able to impact their child well-being.

Several important contributions are offered by this paper. The main results highlight that there was a significant relationship between the parenting stress and perceived children social behavior problem as well as the result are supported by a few past researches. Hence, noting that the higher the parenting stress, there is a high possibility for the children be diagnosed of having children social behavior problem. This means that the stress level of the particular parents might likely to create some unfavorable outcome causes their child behavioral problem. Hence, the result gives aware to the frontline service provider to be observant for those stress working mothers, who have high level of parenting stress, does not feel good towards their interaction with their child, and having trouble in handling their difficult child in order to give them the social support and grasp the proper service.

Ref. [19] give a comment that mother who gets more stress might perceive their child to have extra-ordinary problem behavior, such that the essence of providing working mothers with more training programs such as stress management, way of parenting has become increasingly crucial issue. Regarding the stress management and female employment, counseling or public health campaign should be designed either by government or other than governmental organizations for educating the working mothers about conducting quality childcare particularly for Chinese family in Malaysia in the aspect of handling stress. The specificity of campaign is to enhance quality of family childcare by reducing working mothers' stress level as well as the risk of negative family concern.

Doing stress management programmed is to understand the science of balancing work and family. The findings shows that the factors of parenting stress is higher in the children domain rather than in parent domain, that is, putting extra effort on improving mothers' capability can be relatively effective to leverage out the problem. For instance, parent training program might be useful for parent to manage their child.

Most of the time, the dual responsibility is not an easy job, however. The excessive workload also able to influence a mother's emotion that creates negative perception on children. From the part of child domain, it referred to the children who have difficult temperament. The results showed the child characteristic and parental dysfunctional also contribute to the parenting stress.

By this study, it suggests a caution to the policy makers to create an early intervention for those working mothers in controlling their emotion. It is valuable to persuade childcare centre to promote the prevention programs for reducing the preschool child behavior problem. The young children can be taught the way to solve the problem and act independently 
sometimes. Thus, based on this concept, preschools therefore are recommended to organize stress prevention program for preschoolers in term of added syllabus in teaching social skill, problem solving and emotional control. Additionally, effective program of early intervention should be considered in order to prevent the development of the problem. For those children who have been detected having social problematic behavior, an intervention should be done in their early age for reducing the risk of having children social behavior problem from become currently problem when they reached primary school.

The study also showed the sub domains of the parenting stress (parental distress, parent child dysfunctional interaction and difficult child) are related to the perceived children social problem behavior. This result suggests that three factors are able to influence their children problem. It could be predicted that the stress of parenting not only from child domain but also from the parenting domain which refers to the stress from the mother herself such as life stress and dissatisfaction relationship with spouse. However, the number of this problem can be reduced through education by using media (e.g. publication, broadcasting, TV shows), NGO and government agency should actively plan and recommend it to media even though media is commercial base. Media education is extremely long lasting (it takes more than years), but it instead communicate with people easily than official conference or seminar.

Numbers of child might have a potential that implicitly increase the effect of parenting stress. Present result gives some suggestion for the policy maker that to target or focus on the certain group of people - working mothers who have had more children arc at high risk for having more parenting stress.

Childcare demands different level of parenting skills specifically while there are different types of child growth period. Although mothers have been a bit skilful in looking after the second or third child due to the first giving birth experience, fulfilling the demands of children has become rather difficult. This is because more children require more effort in taking care of them. The stress resulted by heavy house chores and emotional burden is multiplied, making the workings mother suffer from unsatisfactory living experience. For Chinese society, a recommendation is, there is no argument that Chinese chamber has relatively bigger responsibility and is responsible for educating Chinese family to transit their tradition or culture (to erase those unwanted). Letting women to solely handle the job childcare is harmful. It is because the whole society has been totally changed, compare as couple of decades ago, husband must and have to share the duty of childcare but not only to be a bread winner.

The findings indicate the linkage between the household income and parenting stress. The negative relationship shows the higher the household income, the lower the level of parenting stress. In general socioeconomic view, financial burden is able to stress up a person. This situation has become more severe since competition and cost of living increase steadily in the recent years.

The study actually promotes the importance for the counselors or parents educators to put the factors of household financial under the consideration during their practices. However, private sectors can play their role in giving a helping hand. For example, financial institutions recommended to organize several talk for women (for free if possible) to help them to manage their financial position. Financial management has been more important in recent day. It does not only have particular meaning for man but also necessary for female. For example, the main reason makes female to involve in labor force is getting income for easing family financial burden, without necessary knowledge about financial management or assistance given by the public, the problem of financial burden may not be solved entirely. In the perspective of career service, career or occupational training programs should be launched for improving women competitiveness in general labor market in the point of view in increasing their income level. Furthermore, the government and relevant women rights organization should do their best to protect women rights against social biases regarding maternal employment. It is because the stress level of working mothers may be higher than usual when their children are in early age and this can be one of the reasons to get layoff, which in turn deteriorate benefits of female employment associated with discrimination.

Surprisingly, the findings showed the more the working hours, the lower the parenting stress of the working mothers. The result contrasted to the prior findings. This result give an interesting outcome that alerts policy makers and citizens that people who works longer hours, the lesser the time exposure to their children, the stress could be reduced. Consequently, it gives a guideline for future researchers to explore the accuracy of the result.

This research is firstly designed for measuring the relation between the stress level of working mothers and children social problem behavior. The main purpose of this study is to help future researchers and organizations to understand contemporary challenges of social development particularly in the perspective of the health of Chinese family.

This study holistically shows the direction of what current family development should be focus on, by create a harmony family atmosphere in reducing working mothers' parenting stress level while helping children to tackle difficulties. The globalization forces women to involve in labor market and this trend is unavoidable, government agencies and organizations then should carry out certain strategies to overcome negative effect of transition of labor market. Yet, the current study gives indication and direction, ensuring the policies to be adjustable such that the final goal, namely, social welfare on women basis, can be achievable and achieved.

\section{A. Abbreviations and Acronyms}

PSI-SF - Parenting Stress Index - Short Form; ECBI - Eyberg Child Behavior Inventory.

\section{CONCLUSION}

As a conclusion, finding from this research obviously explained the parents' stress is contributed to the problematic behavior amongst child in family. In addition, the time that being in office or workplace become a factor that assisting mother to reduce stress in Chinese culture. It is perhaps, the mother has less time with child which for them it can cause 
towards stress. Then, the household income is also contributed towards parenting stress. Moreover, the consideration on time flexibility amongst working mothers can be a significant strategy in reducing their stress.

\section{ACKNOWLEDGMENT}

I would like to express my profound gratitude to my supervisor Wan Marzuki Wan Jaafar (PhD) as well as respondents who are involved in this research, for their exemplary guidance in completing this research.

\section{REFERENCES}

[1] J. Bowlby, "Attachment and loss," Separation, New York: Basic Books, vol. 1, 1973.

[2] D. Ary, L. C. Jacobs, and C. Sorensen, Introduction to Research in Education, California: Thomson Wadsworth, 2006.

[3] R. Abidin, "The determinats of parenting behavior," Journal of Clinical Child Psychology, vol. 21, pp. 407-412, 1992.

[4] S. M. Eyberg and D. Pincus, "Eyberg child behavior inventory and sutter-eyberg student behavior inventory: professional manual. odessa," Psychological Assessment Resources, vol. 30, 1990.

[5] H. A. Raikes and R. A. Thompson, "Efficacy and social support as predictors of parenting stress among families in poverty," Infant Mental Health Journal, vol. 26, no. 3, pp. 177-194, 2005.

[6] S. E. Taylor, R. L. Repetti, and T. Seeman, "Health psychology: What is an unhealthy environment and how does it get under the skin?" Annual Review of Psychology, vol. 48, pp. 411-447, 1997.

[7] P. Joshi and K. Bogen, "Nonstandard schedules and young children's behavioral outcomes among working low-income families," Journal of Marriage and Family, vol. 69, pp. 119-756.

[8] Y. C. Chan, "Parenting stress and social support of mothers who physically abuse their children in Hong Kong," Child Abuse and Neglect, vol. 18, pp. 261-269, 1994.

[9] M .Ostberg and B. Hagekull, "A structural modeling approach to the understanding of parenting stress," Journal of Clinical Child Psychology, vol. 29, pp. 615-625, 2000.

[10] J. Blacher and L. L. Mclntyre, "Syndrome specificity and behavioural disorders in young adults with intellectual disability: Cultural differences in family impact," Journal of Intellectual Disability Research, vol. 50, no. 3, pp. 184- 198, 2006.

[11] N .Guajardo, G. Snyder, and R. Petersen, "Relationships among parenting practices, parental stress, child behaviour, and children's social-cognitive development," Infant and Child Development, vol. 18 no. 1, pp. 37-60, 2009.

[12] L. G. Anthony, B. H. Anthony, D. N. Glanville, D. Q. Caiman, C. Waanders, and S. Shaffer, "The relationship between parenting stress, parenting behaviour and preschoolers' social competence and behaviour problems in the classroom," Infant and Child Development, vol. 14, pp. 133-154, 2005.

[13] C. T. Beck, "Maternal depression and child behaviour problems: a meta-analysis," Journal of Advanced Nursing, vol. 29, no. 3, pp. $623-629,1990$

[14] R. Forehand, G. Brody, "The association between parental pesona/marital adjustment and parent-child interactions in clinic sample," Behaviour Research and Therapy, vol. 23, pp. 211-212, 1995.

[15] D. Oyserman, D. Bybee, and C. Mowbray, "Influences of maternal mental illness on psychological outcomes for adolescent children," Journal of Adolescence, vol. 25, pp. 587-602, 2002.

[16] P. Brennan, C. Hammen, M. Anderson, W. Bor, J. Najman, and G. M. Williams, "Chronicity, severity, and timing of maternal depressive symptoms: Relationships with child outcomes at age 5," Developmental psychology, vol. 36, pp. 759-766, 2000.

[17] J. Zeijl, J. Mesman, M. N. Stollq, L. R. Alink, M. H. IJzendoorn, M. J. B. Kranenbrug et al., "Differential susceptibility to discipline: the moderating effect of child temperament on the association between maternal discipline and early childhood externalizing problems," Journal of Family Psychology, vol. 21, no. 4, pp. 626, 2007.

[18] R. Hastings, H. Kovshoff, N. Ward, F. D. Espinosa, T. Brown, and B Remington, "System analysis of stress and positive perceptions in mothers and fathers of preschool children with autism," Journal of Autism and Developmental Disorders, vol. 35, no. 5, pp. 635-644, 2005.

[19] K. A. Crnic, C. Gaze, and C. Hoffman, "Culmulative parenting stress across the preschool period: Relations to maternal parenting and child behaviour at age 5," Infant and Child Development, vol. 14, pp. 177-132, 2005.

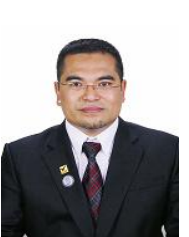

Wan Marzuki Bin Wan Jaafar is a senior lecturer from the Department of Counselor Education and Counseling Psychology, Faculty of Educational Studies, University Putra Malaysia. $\mathrm{He}$ is specialized in counseling supervision and development of psychological instrument His research interests are in counselor education and supervision; development of psychological instrument; career counseling; and computer application in education. 